\title{
Characteristics of women undergoing repeat induced abortion
}

\author{
William A. Fisher, Sukhbir S. Singh, Paul A. Shuper, Mark Carey, Felicia Otchet, \\ Deborah MacLean-Brine, Diane Dal Bello, Jennifer Gunter
}

13 See related article page 653

Abstract

Background: Although repeat induced abortion is common, data concerning characteristics of women undergoing this procedure are lacking. We conducted this study to identify the characteristics, including history of physical abuse by a male partner and history of sexual abuse, of women who present for repeat induced abortion.

Methods: We surveyed a consecutive series of women presenting for initial or repeat pregnancy termination to a regional provider of abortion services for a wide geographic area in southwestern Ontario between August 1998 and May 1999. Self-reported demographic characteristics, attitudes and practices regarding contraception, history of relationship violence, history of sexual abuse or coercion, and related variables were assessed as potential correlates of repeat induced abortion. We used $\chi^{2}$ tests for linear trend to examine characteristics of women undergoing a first, second, or third or subsequent abortion. We analyzed significant correlates of repeat abortion using stepwise multivariate multinomial logistic regression to identify factors uniquely associated with repeat abortion.

Results: Of the 1221 women approached, 1145 (93.8\%) consented to participate. Data regarding first versus repeat abortion were available for 1127 women. A total of $68.2 \%, 23.1 \%$ and $8.7 \%$ of the women were seeking a first, second, or third or subsequent abortion respectively. Adjusted odds ratios for undergoing repeat versus a first abortion increased significantly with increased age (second abortion: 1.08, 95\% confidence interval [Cl] 1.04-1.09; third or subsequent abortion: $1.11,95 \% \mathrm{Cl} 1.07-1.15)$, oral contraceptive use at the time of conception (second abortion: 2.17, 95\% Cl 1.52-3.09; third or subsequent abortion: $2.60,95 \% \mathrm{Cl}$ $1.51-4.46)$, history of physical abuse by a male partner (second abortion: 2.04, 95\% Cl 1.39-3.01; third or subsequent abortion: $2.78,95 \% \mathrm{Cl} 1.62-4.79)$, history of sexual abuse or violence (second abortion: 1.58, 95\% Cl 1.11-2.25; third or subsequent abortion: $2.53,95 \% \mathrm{Cl} 1.50-4.28)$, history of sexually transmitted disease (second abortion: 1.50, 95\% Cl 0.98-2.29; third or subsequent abortion: 2.26, 95\% $\mathrm{Cl} 1.28-4.02)$ and being born outside Canada (second abortion: 1.83, 95\% Cl 1.19-2.79; third or subsequent abortion: $1.75,95 \% \mathrm{Cl}$ 0.90-3.41).

Interpretation: Among other factors, a history of physical or sexual abuse was associated with repeat induced abortion. Presentation for repeat abortion may be an important indication to screen for a current or past history of relationship violence and sexual abuse.

CMA/ 2005;172(5):637-41
$\mathrm{R}$ epeat pregnancy termination procedures are common in Canada (where $35.5 \%$ of all induced abortions are repeat procedures) $)^{1,2}$ and the United States (where $48 \%$ of induced abortions are repeat procedures). ${ }^{3-7}$ Rates of repeat induced abortion increased in both countries for an initial period after abortion was legalized, as a result of an increase in the number of women who had access to a first, and consequently to repeat, legal induced abortion. ${ }^{1,6,8,9}$ At present, rates of initial and repeat abortion in Canada and the United States appear to be stabilizing. ${ }^{2,7}$

Research concerning characteristics of women who undergo repeat induced abortions has been limited in scope. In a literature search we identified fewer than 20 studies in this area published over the past 3 decades. However, available research has shown several consistent findings. Women undergoing repeat abortions are more likely than those undergoing a first abortion to report using a method of contraception at the time of conception. ${ }^{7,8,10,11}$ In addition, women seeking repeat abortions report more challenging family situations than women seeking initial abortions: they are more likely to be separated, divorced, widowed or living in a common-law marriage, and to report difficulties with their male partner. ${ }^{1,5,8,11,12}$ They also are older, ${ }^{7,13}$ have more children ${ }^{1,5,13}$ and are more often nonwhite ${ }^{7,11,13}$ than women seeking initial abortions.

There is little evidence to suggest that women seeking repeat abortion are using pregnancy termination as a method of birth control. ${ }^{1,5,6,8,11}$ Evidence also does not indicate that women seeking repeat abortion are psychologically maladjusted. ${ }^{8,13}$

Our literature review showed that many studies of repeat abortion are 20 to 30 years old and are based on data collected when abortion was a newly legalized procedure. ${ }^{5,11}$ Furthermore, in studies of correlates of repeat abortion the investigators did not examine a range of personality characteristics that are known to influence women's reproductive health outcomes, ${ }^{14,15}$ including attitudes about sexuality, ${ }^{14}$ health locus of control, ${ }^{16,17}$ degree of social integration, ${ }^{16}$ attitudes about contraception ${ }^{18,19}$ and history of sexual or physical abuse. ${ }^{20-22}$ The objective of the current study was to identify characteristics of women who undergo repeat induced abortion. 


\section{Methods}

We surveyed a consecutive series of women presenting for induced abortion at the London Health Sciences Centre, London, Ont., the regional provider of abortion services for a wide geographic area, between August 1998 and May 1999. Women were given a description of the study at the beginning of their initial appointment at the clinic and were asked to consider participating. They were assured that their identity and responses would remain confidential and that their decision concerning participation would not affect their care in any way. Participants completed a confidential self-report questionnaire in a private setting at the clinic before receiving any counselling or other intervention. These procedures were approved by the University of Western Ontario's Office of Research Ethics.

The participants completed a 65 -item self-report questionnaire. We developed this instrument on the basis of the research literature ${ }^{1,7,8,15-18}$ as a means of collecting data concerning correlates of repeat induced abortion with a brief assessment that could be administered readily in a clinical setting. Most questionnaire items represented face-valid single-item self-reports of demographic or personal characteristics that were developed and pilot tested specifically for this investigation and in accordance with standard procedures for research in this area. ${ }^{18,23,24}$

The questionnaire included initial items assessing the woman's demographic characteristics, relationship status, and reports of relationship conflict, a history of sexual abuse or coercion, or physical abuse by a male partner at any time in the past. Subsequent items assessed attitudes and practices regarding contraception, including method of contraception (if any) used at the time of conception, whether the woman had missed taking any birth control pills during the month that conception occurred, whether she had taken formal sex education classes in high school, and history of STD and HIV testing. Self-report items also sought information regarding past pregnancy and abortion.

We used one-way analysis of variance to compare the mean age of women presenting for first, second, or third or subsequent abortions and $\chi^{2}$ tests for linear trend to examine other characteristics. Conceptually and clinically significant correlates of repeat induced abortion were then entered into a stepwise multivariate multinomial logistic regression to identify factors that were significantly and uniquely associated with number of induced abortions. ${ }^{25}$ This analysis allows for a reference category (women presenting for a first abortion) to be compared with 2 or more other reference categories (women presenting for a second abortion and women presenting for a third or subsequent abortion). Characteristics are entered into the regression analysis beginning with the characteristic most strongly associated with the reference category, and additional characteristics are added in order of decreasing strength of association until a characteristic is entered that is not significantly associated with the reference categories under study. ${ }^{25}$

\section{Results}

Of the 1221 women approached, 1145 (93.8\%) provided informed consent to participate in the study. Data for 18 women were excluded from the statistical analyses owing to missing responses that precluded stratification into initial versus repeat abortion categories, resulting in a final sample of 1127 . Of the 1127 women, $769(68.2 \%)$ were undergoing a first induced abortion, $260(23.1 \%)$ a second abortion, and $98(8.7 \%)$ a third or subsequent abortion. The participants were young (mean age 23.65 years [standard deviation (SD) 6.36 years]), primarily white (971 [86.2\%]) and primarily Canadian born (962 [85.4\%]).

More than a quarter of the participants (288 [26.4\%]) reported significant conflict in their relationship with the man involved in their pregnancy, and 1 in 5 (218 [19.5\%]) reported having been physically abused at least once by a male partner. More than a quarter (301 [27.0\%]) reported that they had experienced sexual abuse or sexual violence at least once in the past.

Most of the participants (1013 [90.1\%]) had used contraception at some point in the past. Although most (947 $[87.8 \%])$ felt that oral contraception is a good form of birth control, more than half $(565[52.6 \%])$ felt that the best form of birth control would be one that they did not have to remember to take. Nearly 1 in 5 women (196 [18.3\%]) indicated that they sometimes could not afford to buy their method of birth control. More than half (616 [55.3\%]) reported that they or their partner had been using a method of birth control at the time of conception, with use of condoms (371 [60.2\%]) and orally administered contraceptives (244 [39.6\%]) predominating.

Women seeking a second abortion (mean age 25.3 [SD 6.2] years) or a third or subsequent abortion (mean age 26.7 [SD 5.7] years) were significantly older than those seeking a first abortion (mean age 22.7 [SD 6.3] years) $(p<0.05$, Tukey's honestly significant difference test) ${ }^{26}{ }^{2}$ Women undergoing repeat abortion were also more likely than those undergoing a first abortion to be born outside Canada and to be black or of Middle Eastern ethnicity $(p<0.025)$ (Table 1).

Women undergoing repeat abortion were more likely than those seeking a first abortion to report having been physically abused by a male partner, having experienced sexual abuse or sexual violence $(p<0.001)$ and having experienced substantial conflict with the man involved in their current pregnancy $(p<0.01)$. They were less likely to report that they had "lots of friends" $(p<0.001)$, were a "traditional woman" $(p<0.025)$ and had "lots of plans for the future" $(p<0.001)$.

Women presenting for repeat abortion were less likely than those seeking an initial abortion to report that they had had formal sex education $(p<0.001)$. They were more likely to have had an STD, to have undergone HIV testing and to have given birth $(p<0.001)$.

Finally, women presenting for repeat abortion were more likely than those presenting for a first abortion to report that they had used birth control at some point $(p<$ 0.001 ), that they or their partner were using birth control at the time of conception $(p<0.05)$ and that they were using the birth control pill when conception occurred $(p<$ 0.001). (Note, however, that reports of having missed pills during the month in which conception occurred did not 
Table 1: Correlates of repeat pregnancy termination: $\chi^{2}$ tests for linear trend

\begin{tabular}{|c|c|c|c|c|}
\hline \multirow[b]{2}{*}{ Correlate } & \multicolumn{3}{|c|}{ No. $(\%)$ of women } & \multirow[b]{2}{*}{$p$ value } \\
\hline & $\begin{array}{l}\text { First abortion } \\
\quad n=769\end{array}$ & $\begin{array}{l}\text { Second abortion } \\
\quad n=260\end{array}$ & $\begin{array}{c}\text { Third or subsequent } \\
\text { abortion } \\
n=98\end{array}$ & \\
\hline Born outside Canada & $99(12.9)$ & $49(18.8)$ & $18(18.4)$ & $<0.025$ \\
\hline \multicolumn{5}{|l|}{ Ethnicity } \\
\hline Black & $23 \quad(3.0)$ & $16 \quad(6.2)$ & $9 \quad(9.3)$ & $<0.001$ \\
\hline Middle Eastern & $4 \quad(0.5)$ & $3(1.2)$ & $3(3.1)$ & $<0.025$ \\
\hline \multicolumn{5}{|l|}{ Education } \\
\hline $\begin{array}{l}\text { Completed community college, nursing } \\
\text { school or technical school }\end{array}$ & $129(16.8)$ & $66(25.4)$ & $27(27.6)$ & $<0.001$ \\
\hline Currently attending high school & $142(18.5)$ & $22(8.5)$ & $3(3.1)$ & $<0.001$ \\
\hline Completed some high school & $73 \quad(9.5)$ & $34(13.1)$ & $14(14.3)$ & $<0.05$ \\
\hline No formal education & $2 \quad(0.3)$ & $2(0.8)$ & $3(3.1)$ & $<0.01$ \\
\hline \multicolumn{5}{|l|}{ Living arrangements } \\
\hline Lives with children & $193(25.2)$ & $105(40.5)$ & $45(45.9)$ & $<0.001$ \\
\hline Lives with parent(s) & $284(37.0)$ & $54(20.8)$ & $15(15.3)$ & $<0.001$ \\
\hline Lives with other friends or relatives & $96(12.5)$ & $28(10.8)$ & $5 \quad(5.1)$ & $<0.05$ \\
\hline Lives with common-law partner & $86(11.2)$ & $34(13.1)$ & $19(19.4)$ & $<0.05$ \\
\hline \multicolumn{5}{|l|}{ Relationship status } \\
\hline Partner or boyfriend & 367 (47.9) & $112(43.4)$ & $36(36.7)$ & $<0.025$ \\
\hline Divorced & $18 \quad(2.3)$ & $12(4.7)$ & $6 \quad(6.1)$ & $<0.025$ \\
\hline \multicolumn{5}{|l|}{ Relationship conflict and history of abuse } \\
\hline $\begin{array}{l}\text { Substantial conflict and fights with man } \\
\text { involved in current pregnancy }\end{array}$ & $181(24.0)$ & $73(29.6)$ & $34(35.4)$ & $<0.01$ \\
\hline $\begin{array}{l}\text { Good relationship with man involved in } \\
\text { current pregnancy }\end{array}$ & $608(81.0)$ & $189(75.3)$ & $65(68.4)$ & $<0.01$ \\
\hline History of physical abuse by a male partner & $105(13.7)$ & $73(28.9)$ & $40(41.2)$ & $<0.001$ \\
\hline History of sexual abuse or sexual violence & $168(22.0)$ & $90(35.2)$ & $43(45.3)$ & $<0.001$ \\
\hline \multicolumn{5}{|l|}{ Social variables } \\
\hline Has "lots of friends"* & $674(89.4)$ & $208(81.6)$ & $69(71.1)$ & $<0.001$ \\
\hline Is a "traditional woman" $\dagger$ & $386(57.1)$ & $119(51.5)$ & $37(45.7)$ & $<0.025$ \\
\hline Has "Iots of plans for the future" $\ddagger$ & $702(92.7)$ & $231(90.6)$ & $81(85.3)$ & $<0.001$ \\
\hline \multicolumn{5}{|l|}{$\begin{array}{l}\text { Sex education, STDs and practices regarding } \\
\text { contraception }\end{array}$} \\
\hline Took sex education classes in school & $692(91.1)$ & $216(84.4)$ & $78(82.1)$ & $<0.001$ \\
\hline History of STD & $86(11.3)$ & $50(19.5)$ & $27(28.1)$ & $<0.001$ \\
\hline Has been tested for HIV & $323(42.7)$ & $136(52.3)$ & $57(60.6)$ & $<0.001$ \\
\hline Has given birth to 1 or more children & $276(35.9)$ & $147(56.5)$ & $66(67.3)$ & $<0.001$ \\
\hline History of use of birth control & $673(87.7)$ & $247(95.7)$ & $93(95.9)$ & $<0.001$ \\
\hline $\begin{array}{l}\text { Self or partner or both were using birth } \\
\text { control when current pregnancy occurred }\end{array}$ & $397(53.1)$ & $160(62.3)$ & $55(58.5)$ & $<0.05$ \\
\hline $\begin{array}{l}\text { Was using birth control pill when current } \\
\text { pregnancy occurred }\end{array}$ & $137(17.8)$ & $78(30.0)$ & $28(28.8)$ & $<0.001$ \\
\hline \multicolumn{5}{|l|}{ Agreed with following statements } \\
\hline $\begin{array}{l}\text { The best birth control for me would be one } \\
\text { that I don't have to remember to take }\end{array}$ & $353(48.1)$ & $151(59.9)$ & $61(64.9)$ & $<0.001$ \\
\hline $\begin{array}{l}\text { The birth control pill is a good form of } \\
\text { birth control }\end{array}$ & $681(92.5)$ & $204(82.3)$ & $62(67.4)$ & $<0.001$ \\
\hline Sometimes I can't afford to buy birth control & $122(16.3)$ & $50(20.1)$ & $24(25.8)$ & $<0.025$ \\
\hline Birth control pills are too expensive for me & $57 \quad(7.6)$ & $26(10.4)$ & $14(15.2)$ & $<0.025$ \\
\hline
\end{tabular}


differ between the 2 groups.) Women presenting for repeat abortion were more likely to agree that "the best birth control for me would be one that I don't have to remember to take" $(p<0.001)$ and that "birth control pills are too expensive for me" $(p<0.025)$.

Characteristics examined in stepwise multivariate multinomial logistic regression analysis included age, country of origin, living with children, conflict with the man involved in the current pregnancy, history of physical abuse by a male partner, history of sexual abuse or sexual violence, having many friends, having plans for the future, having had formal sex education, having had an STD, use of birth control at the time of conception and oral contraceptive use at the time of conception. The analysis indicated that increased age, oral contraceptive use at the time of conception, history of physical abuse by a male partner, history of sexual abuse or sexual violence, having had an STD and being born outside Canada were uniquely associated, in descending order of strength of association, with undergoing repeat compared with initial abortion (Table 2).

\section{Interpretation}

We found unique associations between repeat induced abortion and increased age, oral contraceptive use, physical abuse by a male partner and history of sexual abuse or sexual violence. Our observations confirm earlier studies indicating an association between repeat abortion and age, ${ }^{7,13}$ relationship conflict ${ }^{1,5,8,11,12}$ and relatively greater contraceptive use, $, 7,10,11$ and go well beyond existing literature ${ }^{1,5,8,11,12}$ in identifying unique associations of a history of relationship violence or of sexual abuse or coercion with repeat abortion. Women presenting for a third or subsequent abortion were more than 2.5 times as likely as those seeking a first abortion to report a history of physical abuse by a male partner or a history of sexual abuse or violence.
Our findings of a relation between repeat abortion and physical abuse by a male partner and sexual abuse or violence suggest continued effects of these factors ${ }^{20-22}$ on women's health outcomes. It is possible that a history of physical abuse by a partner or of sexual abuse or violence results in lasting psychologic changes that lead the woman to decide that carrying a pregnancy to term is not desirable. It is also possible that physical or sexual abuse is an indicator of the existence of social environment factors that were initially conducive to abuse and that are currently conducive to the decision to terminate a pregnancy in the event that one occurs. Women undergoing repeat induced abortion do not, however, appear to be inconsistent users of contraception compared with women undergoing a first abortion. In fact, we found that the former were somewhat more likely than the latter to report using birth control at the time of conception.

Limitations of our study include reliance on self-reports of sensitive issues (e.g., use of contraceptives at the time of conception), which could result in social desirability response bias, and use of single items to measure most constructs in order to create brief assessments usable in clinical settings. Although considerable validity research attests to the accuracy of self-reports in the area of sexual and reproductive health behaviour, ${ }^{23,27,28}$ our study is based entirely on self-reports that are potentially subject to response bias and not subject to independent verification.

In summary, a key finding of our study is that women undergoing repeat induced abortion were considerably more likely than those undergoing a first abortion to have experienced physical abuse by a male partner or sexual abuse or coercion. These results emphasize the need for screening for a current or past history of physical or sexual abuse at the time of presentation for abortion. ${ }^{29,30}$ Such screening could result in offers of referral and counselling that might prove helpful to the woman in dealing with a history of physical or sexual abuse, and could potentially help avert a future abortion.

\begin{tabular}{|c|c|c|c|c|}
\hline \multirow[b]{2}{*}{ Predictor } & \multicolumn{2}{|c|}{ Second abortion } & \multicolumn{2}{|c|}{ Third or subsequent abortion } \\
\hline & $\begin{array}{l}\text { Unadjusted } \\
\text { OR }(95 \% \mathrm{CI})\end{array}$ & $\begin{array}{c}\text { Adjusted } \\
\text { OR }(95 \% \mathrm{CI})\end{array}$ & $\begin{array}{l}\text { Unadjusted } \\
\text { OR }(95 \% \mathrm{CI})\end{array}$ & $\begin{array}{c}\text { Adjusted } \\
\text { OR }(95 \% \mathrm{Cl})\end{array}$ \\
\hline Age & $1.07(1.04-1.09)$ & $1.08(1.04-1.09)$ & $1.10(1.06-1.13)$ & $1.11(1.07-1.15)$ \\
\hline $\begin{array}{l}\text { Self or partner or both were using } \\
\text { birth control when pregnancy } \\
\text { occurred }\end{array}$ & $1.98(1.43-2.73)$ & $2.17(1.52-3.09)$ & $1.85(1.15-2.97)$ & $2.60(1.51-4.46)$ \\
\hline $\begin{array}{l}\text { History of physical abuse by a male } \\
\text { partner }\end{array}$ & $1.92(1.41-2.61)$ & $2.04(1.39-3.01)$ & $2.93(1.89-4.54)$ & $2.78(1.62-4.79)$ \\
\hline $\begin{array}{l}\text { History of sexual abuse or sexual } \\
\text { violence }\end{array}$ & $2.55(1.81-3.59)$ & $1.58(1.11-2.25)$ & $4.41(2.80-6.94)$ & $2.53(1.50-4.28)$ \\
\hline History of STD & $1.90(1.30-2.78)$ & $1.50(0.98-2.29)$ & $3.08(1.87-5.06)$ & $2.26(1.28-4.02)$ \\
\hline Born outside Canada & 1.57 & $1.83(1.19-2.79)$ & $1.52(0.87-2.64)$ & $1.75(0.90-3.41)$ \\
\hline
\end{tabular}

Note: $\mathrm{OR}=$ odds ratio, $\mathrm{Cl}=$ confidence interval.

*Reference group is "initial abortion." For all factors entered, $p<0.05$. 
This article has been peer reviewed.

From the Departments of Psychology (Fisher, Shuper, Otchet) and Obstetrics and Gynaecology (Fisher, Singh, Carey, Otchet, Gunter), University of Western Ontario, and the London Health Sciences Centre (Singh, Carey, Otchet, MacLeanBrine, Dal Bello), London, Ont. Jennifer Gunter is currently with the Department of Obstetrics and Gynecology, University of Colorado, Denver, Colo.

Competing interests: William Fisher is the recipient of a Research Scientist in Reproductive Health Behavior award funded by Janssen-Ortho (Canada).

Contributors: William Fisher contributed to study conception and design and data analysis and to writing of the draft. Sukhbir Singh and Paul Shuper contributed to data analysis and interpretation and to drafting and revising the article. Mark Carey and Felicia Otchet contributed to study conception and design and data acquisition, and reviewed and revised the manuscript. Deborah MacLean-Brine and Diane Dal Bello contributed to study design and data acquisition, and read and contributed revisions to the manuscript. Jennifer Gunter contributed to study design and data acquisition, and read and revised the manuscript. All of the authors gave their final approval of the version submitted to be published.

Acknowledgements: We acknowledge the assistance of Larry Stitt with the statistical analyses.

This research was supported by a Janssen-Ortho (Canada) Research Scientist in Reproductive Health Behavior award and an Academic Enrichment Fund award, from the Department of Obstetrics and Gynaecology, University of Western Ontario, to William Fisher and Mark Carey respectively, and by a Gynecologic Oncology Research Fund award from the London Health Sciences Centre to Mark Carey.

\section{References}

1. Millar WJ, Wadhera S, Henshaw SK. Repeat abortions in Canada, 1975-93. Fam Plann Perspect 1997;29:20-4.

2. Statistics Canada. Therapeutic abortion survey. Canadian Institute for Health Information (custom tabulation). Ottawa: Statistics Canada; 2003.

3. Alan Guttmacher Institute. Facts in brief. Induced abortion. New York: The Institute; 2002. Available: www.agi-usa.org/pubs/fb_induced_abortion.html (accessed 2004 Oct 6).

4. Elam-Evans LD, Strauss LT, Herndon J, Parker WY, Whitehead S, Berg CJ Abortion surveillance - United States, 1999. MMWR Surveill Summ 2002;51 (9):1-9,11-28. Available: www.cdc.gov/mmwr/preview/mmwrhtml/ss5109a1 .htm (accessed 2004 Oct 6).

5. Steinhoff PG, Smith RG, Palmore JA, Diamond D, Chung CS. Women who obtain repeat abortions: a study based on record linkage. Fam Plann Perspect 1979; 11:30-8.

6. Titze C. Repeat abortions - Why more? Fam Plann Perspect 1978;10:286-8.

7. Westfall JM, Kallail KJ. Repeat abortion and use of primary care health services. Fam Plann Perspect 1995;27:162-5.

8. Berger C, Gold D, Andres D, Gillett P, Kinch R. Repeat abortion: Is it a problem? Fam Plann Perspect 1984;16:70-7.

9. Henshaw SK, Morrow E. Induced abortion: a world review, 1990. Int Fam Plann Persp 1990;16(2):59-65,76.

10. Schneider SM, Thompson DS. Repeat aborters. Am 7 Obstet Gynecol 1976; 126:316-20.
11. Bracken MB, Hachamovitch M, Grossman G. Correlates of repeat induced abortions. Obstet Gynecol 1972;40:816-25.

12. Holmgren K. Repeat abortion and contraceptive use. Report from an interview study in Stockholm. Gynecol Obstet Invest 1994;37:254-9.

13. Freeman EW, Rickels K, Huggins GR, Celso-Ramon G, Polin J. Emotional distress patterns among women having first or repeat abortions. Obstet Gynecol 1980;55:630-6.

14. Fisher WA, Byrne D, Kelley K, White LA. Erotophobia-erotophilia as a dimension of personality. 7 Sex Res 1988;25:123-51.

15. Fisher WA, Fisher JD. Understanding and promoting sexual and reproductive health behavior: theory and method. Annu Rev Sex Res 1998;9:39-76.

16. Oskamp S, Mindick B. Personality and attitudinal barriers to contraception. In: Byrne D, Fisher WA, editors. Adolescents, sex, and contraception. Hillsdale (NJ): Erlbaum; 1983. p. 65-107.

17. Wallston KA, Wallston BS, DeVellis R. Development of the Multidimensional Health Locus of Control (MHLC) scale. Health Educ Monogr 1978;6: 161-70.

18. Fisher WA, Boroditsky R, Bridges M. Canadian contraception study 1998. Can 7 Hum Sex 1999;8:161-220.

19. Byrne D, Kelley K, Fisher WA. Unwanted teenage pregnancies: incidence, interpretation, and intervention. Appl Prev Psychol 1993;2:101-13.

20. Muehlenhard CL, Highby BJ, Lee RS, Bryan TS, Dodrill WA. The sexual revictimization of women and men sexually abused as children: a review of the literature. Annu Rev Sex Res 1998;9:177-223.

21. Campbell JC. Health consequences of intimate partner violence. Lancet 2002; 359:1331-5.

22. Deitz PM, Spitz AM, Anda RF, Williamson DF, McMahon PM, Santelli JS et al. Unintended pregnancy among adult women exposed to abuse or household dysfunction during their childhood. FAMA 2003;282:1359-67.

23. Catania JA, Gibson DR, Chitwood DD, Coates TJ. Methodological problems in AIDS behavioral research: influences of measurement error and participation bias in studies of sexual behavior. Psychol Bull 1990;108:339-62.

24. Dillman DA. Mail and Internet surveys: the tailored design method. 2 nd ed. New York: Wiley and Sons; 1999.

25. Hosmer DW, Lemeshow S. Applied logistic regression. New York: Wiley and Sons; 1989.

26. Winer BJ. Statistical principles in experimental design. 2nd ed. New York: McGraw-Hill; 1971

27. Seal DW. Interpartner concordance of self-reported sexual behavior among college dating couples. 7 Sex Res 1997;1:39-55.

28. Kinsey AC, Pomeroy WB, Martin CE, Gebhard PH. Sexual behavior in the buman female. Philadelphia: Saunders; 1953

29. Wiebe ER, Janssen P. Universal screening for domestic violence in abortion Womens Health Issues 2001;11:436-41.

30. Glander SS, Moore ML, Michielutte R, Parsons LH. The prevalence of domestic violence among women seeking abortion. Obstet Gynecol 1998;91: 1002-6.

Correspondence to: Dr. William A. Fisher, Departments of Psychology and of Obstetrics and Gynaecology, Social Sciences Centre, University of Western Ontario, London ON N6A 5C2;

fisher@uwo.ca 